Brit. Heart F., 1967, 29, 758.

\title{
Time Relation Between Two Pacemakers in Atrial Parasystole
}

\author{
S. D. MOULOPOULOS AND D. A. SIDERIS ${ }^{\star}$ \\ From the Department of Clinical Therapeutics, University of Athens, School of Medicine, Athens, Greece
}

The term "parasystole" denotes an arrhythmia, in which two pacemakers drive the myocardium independently. It is possible, however, for an ectopic focus to give rise to both a parasystolic and an extrasystolic rhythm, the latter usually in the form of bigeminy or trigeminy (Scherf and Schott, 1930; Schamroth, 1966).

Two cases of a complex arrhythmia are presented here. Their analysis on the basis of the synchronization phenomenon may aid the understanding of the mechanism of parasystole.

"Synchronization" implies that two oscillating systems with slightly different idiofrequency acquire the same frequency when they function either in phase or at a certain phase difference. Synchronization may exist when the two frequencies are either approximately equal or in simple mathematical relation $(3: 2,2: 1$, etc.).

Some analogy of the coupling between oscillators to the interplay between different autochthonous pacemakers in the heart was previously suggested by van der Pol and van der Mark (1929) and has also been pointed out by Grant (1956). The hypothesis may help to provide a relatively simple explanation of complex arrhythmias.

\section{CASE REPORTS}

Case 1. An 80-year-old woman was treated in hospital for ischæmic heart disease with congestive failure.

On the electrocardiogram (Fig. 1a) two $P$ waves $\left(P_{1}\right.$ and $\left.P_{2}\right)$, different in shape, alternate, the $P_{1}-P_{2}$ interval being shorter than the $P_{2}-P_{1}$. The $P_{1}-R$ interval is longer $\left(0 \cdot 14-0 \cdot 15 \mathrm{sec}\right.$.) than the $P_{2}-R(0 \cdot 11-$ 0.12 sec.). Occasionally there is no ventricular response to the $P_{2}$ wave.

\section{Received October 28, 1966.}

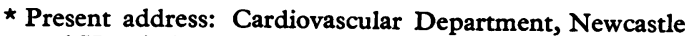
General Hospital, Westgate Road, Newcastle upon Tyne, 4.
Both $\mathbf{P}_{1}-\mathbf{P}_{1}$ and $\mathbf{P}_{2}-\mathbf{P}_{2}$ intervals are almost constant, around $1300 \mathrm{msec}$. The $\mathbf{P}_{1}-\mathbf{P}_{2}$ interval usually varies between 380 and 540 msec., but rare longer $P_{1}-P_{2}$ intervals may result from an early appearance of $P_{1}$ (rather than from a late appearance of $P_{2}$ ) while the $P_{2}$ rhythm is maintained. The $P_{1}-P_{2}$ interval, abruptly increased at the beginning, thereafter gradually acquires the previous value.

Three days later (Fig. 1b) the $P_{2}$ waves still appear at regular intervals of approximately $1300 \mathrm{msec}$., or a simple multiple of this value. The remaining $P$ waves, however, appear at more or less random intervals.

The regularity of $P_{2}$ waves in this case, while the appearance of the remaining seems quite unpredictable, indicates that $P_{2}$ is produced by a parasystolic focus.

Case 2. A 35-year-old woman, without cardiac symptoms, was admitted for a gynæcological operation. An arrhythmia was found and the electrocardiogram of Fig. 2 obtained.

There are two $P$ waves $\left(P_{1}\right.$ and $\left.P_{2}\right)$ different in shape in the tracing. $P_{1}$ appears at regular intervals of 500 to $760 \mathrm{msec}$. or 1200 to $1520 \mathrm{msec}$. In the longer intervals a $P_{2}$ wave is found between two $P_{1}$ waves. The $P_{2}$ wave appears at varying distances from the $P_{1}$, and at regular intervals of 1320 to $1560 \mathrm{msec}$., or at longer intervals, which are simple multiples of about 1500 msec. (Fig. 2).

The $\mathrm{P}_{2}-\mathrm{P}_{2}$ intervals being multiples of a certain value, together with the varying length of $P_{1}-P_{2}$ intervals, suggests that the $P_{2}$ originates from a parasystolic focus.

However, the $P_{1}-P_{2}$ intervals seem to vary in a special way. After a series of consecutive $P_{1}$ waves (without any $P_{2}$ present in the tracing), one $P_{2}$ wave appears at a distance of about $450 \mathrm{msec}$. from $P_{1}$. Thereafter, each $P_{1}$ wave is followed by a $P_{2}$ wave at a distance which is gradually increasing. The rate of this increase, however, is minimal when the $P_{1}-P_{2}$ interval length reaches approximately $550 \mathrm{msec}$. (Fig. 2). Thus, the difference in length between overlapping $P_{2}-P_{2}$ and $P_{1}-P_{1}$ intervals for the whole tracing was found to vary from a mean of $115 \mathrm{msec}$. for the shortest $P_{1}-P_{2}$ intervals, to 5 msec. for $P_{1}-P_{2}$ intervals of $550-560 \mathrm{msec}$., and again up to $50 \mathrm{msec}$. for the longest $P_{1}-P_{2}$ intervals. 
a
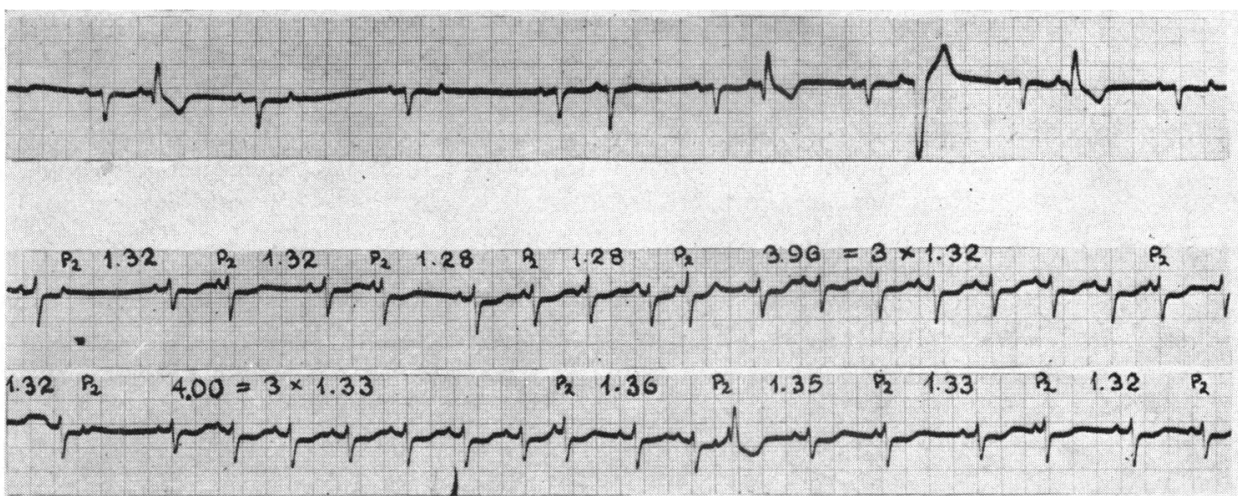

FIG. 1.-Two electrocardiograms (a and b) of Case 1 obtained at a three-day interval (lead V1). Second and third row continuous trasing. Time intervals in sec. $P_{1}-P_{2}$ intervals in (a): 470, 430, 430, 480, $450,460,460$, and $430 \mathrm{msec}$.

\section{Discussion}

In both cases of arrhythmia presented here there are at least two types of $P$ waves, each with its own independent rhythm. The parasystolic nature of the arrhythmia is more or less clear in Fig $1 \mathrm{~b}$ and 2.

The two types of $P$ waves of Case 1 appearing alternately on the tracing of Fig. 1a, with a more or less constant $P_{1}-P_{2}$ interval, suggest a bigeminal type of extrasystolic arrhythmia. The $\mathbf{P}_{1}-\mathrm{P}_{2}$ interval, however, is not strictly constant, and its abrupt change with gradual return to the usual value following a premature $P_{1}$ suggests some degree of "independence" of the $P_{2}$ focus from the $P_{1}$ focus.

On the other hand, the two foci of Case 2 are not entirely independent from each other. Fig. 2 and the correlation of the difference in length between overlapping $\mathrm{P}_{2}-\mathrm{P}_{2}$ and $\mathrm{P}_{1}-\mathrm{P}_{1}$ intervals to the corresponding $\mathrm{P}_{1}-\mathrm{P}_{2}$ interval show clearly that the two foci tend to attain the same frequency when $P_{1}$ precedes $\mathrm{P}_{2}$ by approximately $550 \mathrm{msec}$. So, for some time, the two types of $\mathbf{P}$ wave appear alternately, with an almost constant interval between them, displaying a pattern of arrhythmia which seems apparently to be a form of bigeminy.

The possibility for a parasystolic focus to fire in a bigeminal way has been described by others (Scherf and Schott, 1930; Schamroth, 1966). In these two cases the gradual transition from the one type of arrhythmia to the other is indicated.

The "Wedensky facilitation" phenomenon (Wedensky, 1903), proposed by Schamroth (1966) to explain this alternation of parasystolic and extrasystolic bigeminal rhythm, does not seem to apply in the cases presented here, because of the gradual way in which this alternation takes place.

Instead, the equalization tendency of the rates of

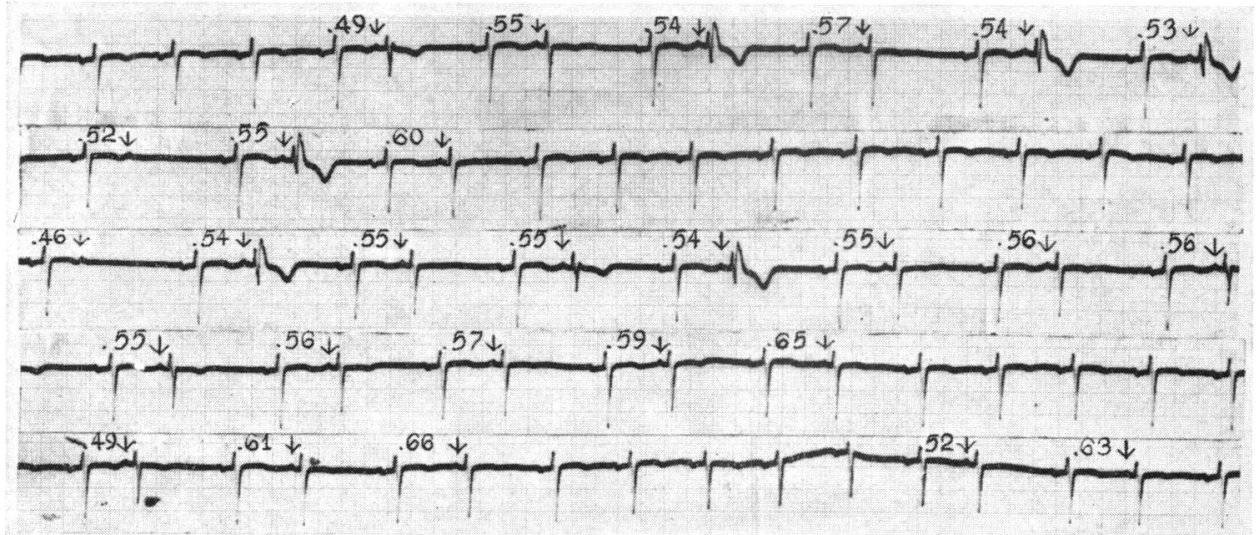

Fig. 2.-Continuous tracing from Case 2. $P_{2}$ is indicated by arrows. The $P_{1}-P_{2}$ intervals are designated in sec. The long intervals without $P_{2}$ are $7500(=1500 \times 5), 4560(=1520 \times 3)$, and $4440(=1480$ $\times 3)$ msec., respectively. 
the two foci when their cycles attain a certain phase difference is the characteristic feature of the synchronization phenomenon, as this was described in frog ventricles (Segers, 1946), in complete A-V block (Segers, Lequime, and Denolin, 1947), and in an electronic pacemaker driving the heart both clinically (Burchell, 1963) and experimentally (Moulopoulos, Kardaras, and Sideris, 1965).

However, some difference between the cases presented here and Segers' cases must be pointed out. In our cases the synchronization does not take place at a zero phase difference, as in Segers' cases, but at a constant phase difference (around $450 \mathrm{msec}$. for Case 1, and around $550 \mathrm{msec}$. for Case 2).

In Segers' cases the synchronization between two anatomically and functionally separate units was observed: between the ventricles of two different frog hearts (Segers, 1946) or between atria and ventricles in complete A-V block (Segers et al., 1947). In the present report, however, it is the activity of two atrial foci which has been followed. There is no obvious explanation for the difference in the two types of synchronization (in phase and at a phase difference).

\section{SUMMARY}

Two cases of atrial parasystole are described. The time relationship of the intervals between the presumably nomotopic and the ectopic foci suggests some similarity with the synchronization of two oscillators.

The two atrial foci show a tendency to function at a steady phase difference. Aberrations from this condition are infrequent and appear or disappear gradually.

\section{REFERENCES}

Burchell, H. B. (1963). Analogy of electronic pacemaker and ventricular parasystole with observations on refractory period, supernormal phase, and synchronization. Circulation, 27, 878.

Grant, R. P. (1956). The mechanism of A-V arrhythmias, with an electronic analogue of the human $\mathrm{A}-\mathrm{V}$ node. Amer. F. Med., 20, 334.

Moulopoulos, S. D., Kardaras, N., and Sideris, D. A. (1965). Stimulus-response relationship in dog ventricle in vivo. Amer. F. Physiol., 208, 154.

Schamroth, L. (1966). Genesis and evolution of ectopic ventricular rhythm. Brit. Heart f., 28, 244.

Scherf, D., and Schott, A. (1930). Parasystolie durch einfache Interferenz mit Ubergang in Bigeminie. Klin. Wschr., 9, 2191.

Segers, M. (1946). Les phénomènes de synchronisation au niveau du cœur. Arch. int. Physiol., 54, 87.

- Lequime, J., and Denolin, H. (1947). Synchronization of auricular and ventricular beats during complete heart block. Amer. Heart f., 33, 685.

van der Pol, B., and van der Mark, J. (1929). The heart beat considered as a relaxation-oscillation, and an electrical model of the heart. Arch. néerl. Physiol., 14, 418.

Wedensky, N. E. (1903). Die Erregung, Hemmung und Narkose. Pflügers Arch. ges. Physiol., 100, 1. 